\title{
Improved Synthesis of 1,2-Bis(trimethylsilyl)benzenes using Rieke-Magnesium or the Entrainment Method
}

\author{
Andreas Lorbach, ${ }^{\text {a }}$ Christian Reus, ${ }^{\text {a }}$ Michael Bolte, ${ }^{\text {a }}$ Hans-Wolfram Lerner, ${ }^{\text {a }}$ \\ and Matthias Wagner ${ }^{\mathrm{a}, *}$ \\ a Institut für Anorganische und Analytische Chemie, Goethe-Universität Frankfurt, Max-von-Laue-Strasse 7, \\ 60438 Frankfurt (Main), Germany \\ Fax: (+49)-69-798-29260; e-mail: Matthias.Wagner@chemie.uni-frankfurt.de
}

Abstract: 1,2-Bis(trimethylsilyl)benzene is the key starting material for the synthesis of efficient benzyne precursors and certain luminescent $\pi$-conjugated materials. We now report that it can be conveniently prepared in tetrahydrofuran from 1,2-dibromobenzene, chlorotrimethylsilane, and either Rieke-magnesium $\left(\mathrm{Mg}^{\mathrm{R}}\right)$ or magnesium turnings in the presence of 1,2-dibromoethane as an entrainer $\left(\mathrm{Mg}^{\mathrm{e}}\right)$. The most important advantages of these new protocols over the currently best-established procedure (1,2-dichlorobenzene, chlorotrimethylsilane, magnesium turnings, hexamethylphosphoramide) lie in the milder reaction conditions $\left(\mathrm{Mg}^{\mathrm{R}}: 0{ }^{\circ} \mathrm{C}, 2 \mathrm{~h}\right.$; $\mathrm{Mg}^{\mathrm{e}}$ : room temperature, $30 \mathrm{~min}$ vs. $100^{\circ} \mathrm{C}, 2$ days) and in the fact that the cancerogenic solvent hexamethylphosphoramide is avoided. Moreover, the improved protocols are also applicable for the highyield synthesis of 1,2,4,5-tetrakis(trimethylsilyl)benzene, 4-fluoro-1,2-bis(trimethylsilyl)benzene, 4chloro-1,2-bis(trimethylsilyl)benzene, and 4,5-dichloro-1,2-bis(trimethylsilyl)benzene.

Keywords: arenes; entrainment method; Grignard reaction; Rieke-magnesium; silanes; silylation

\section{Introduction}

Arylsilanes and their hypervalent derivatives are valuable intermediates in organic synthesis, for example, in borylation ${ }^{[1]}$ or Pd-catalyzed Hiyama cross-coupling reactions. ${ }^{[2]}$ Accordingly, various different methods for the preparation of (functionalized) arylsilanes have been worked out, ranging from the arylation of halosilanes with organolithium or Grignard reagents to the transition metal-mediated silylation of aryl hal- ides with triethoxysilane or triorganosilanes. ${ }^{[3]}$ However, especially the synthesis of sterically encumbered arylsilanes still poses considerable challenges as illustrated by the case of 1,2-bis(trimethylsilyl)benzene (1; Scheme 1), which is only accessible via pathways requiring either highly toxic or very costly chemicals.

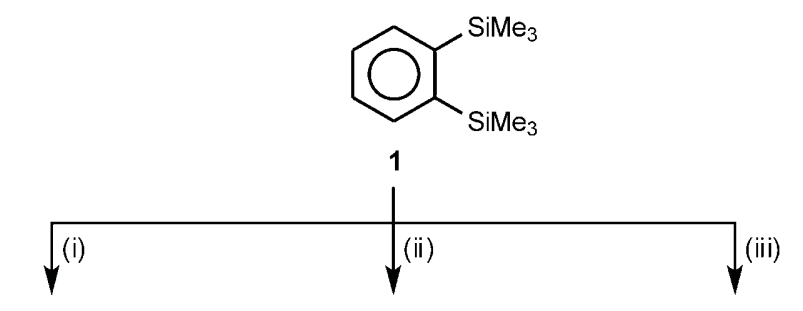<smiles>COc1ccccc1I(O)c1ccccc1</smiles>

A

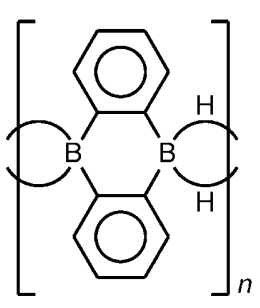

B

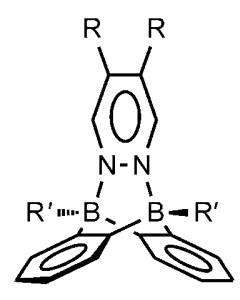

C
Scheme 1. 1,2-Bis(trimethylsilyl)benzene (1) is a key starting material for the preparation of the benzyne precursor $\mathbf{A}$, the polymer building block $\mathbf{B}$, and Lewis-acid catalysts $\mathbf{C}$. (i) $c f$. Ref. $^{[5]}$; (ii) $c f$. Refs. ${ }^{[6,7]}$; (iii) $c f$. Ref. $^{[8]}$

Compound $\mathbf{1}$ is the key starting material for the synthesis of (i) (phenyl)[2-(trimethylsilyl)phenyl]iodonium triflate (A; Scheme 1), one of the most efficient benzyne precursors available to date, ${ }^{[4,5]}$ (ii) 9,10-dihydro-9,10-diboraanthracene (B; Scheme 1), a versatile building block of luminescent boron-doped $\pi$-conjugated polymers, ${ }^{[6,7]}$ and (iii) 9,10-dimethyl-9,10-dihydro-9,10-diboraanthracene, a powerful ditopic Lewis- 
Table 1. Comparison of the yields of 1,2-bis(trimethylsilyl)benzenes obtained with different Grignard methods.

\begin{tabular}{|c|c|c|c|c|c|c|}
\hline Product & $\mathbf{R}^{1}$ & $\mathrm{R}^{2}$ & $\begin{array}{l}\text { Starting Material } \\
\text { Entrainment Approach }{ }^{[a]} \\
\mathrm{X}=\mathrm{Br}\end{array}$ & $\begin{array}{l}\mathrm{X} \\
\mathrm{R}=\mathrm{Br}\end{array}$ & $\begin{array}{l}\text { Fe-Catalyzed Approach }{ }^{[\mathrm{b}]} \\
\mathrm{X}=\mathrm{Br}\end{array}$ & $\begin{array}{l}\text { HMPA Approach } \\
\mathrm{X}=\mathrm{Cl}\end{array}$ \\
\hline 1 & $\mathrm{H}$ & $\mathrm{H}$ & $62 \%$ & $65 \%{ }^{[\mathrm{c}]}$ & $41 \%$ & $75 \%{ }^{[\mathrm{d}]}$ \\
\hline 2 & $X$ & $X$ & $54 \%$ & $80 \%$ & $38 \%$ & $49 \%^{[\mathrm{e}]}$ \\
\hline 4 & $\mathrm{Cl}$ & $\mathrm{Cl}$ & $67 \%$ & $70 \%$ & - & - \\
\hline 5 & $\mathrm{~F}$ & $\mathrm{H}$ & $56 \%$ & $53 \%$ & - & - \\
\hline 8 & $\mathrm{Cl}$ & $\mathrm{H}$ & $59 \%$ & $60 \%{ }^{[\mathrm{f}]}$ & - & - \\
\hline 11 & $\mathrm{Me}$ & $\mathrm{Me}$ & $<10 \%{ }^{[\mathrm{g}]}$ & $10-40 \%{ }^{[\mathrm{h}]}$ & $19 \%$ & $50 \%{ }^{[\mathrm{i}]}$ \\
\hline 12 & $t-\mathrm{Bu}$ & $\mathrm{H}$ & $<10 \%{ }^{[\mathrm{g}]}$ & $0 \%$ & $14 \%$ & - \\
\hline
\end{tabular}

[a] This work.

[b] $\mathrm{Mg}$ powder/Me ${ }_{3} \mathrm{SiCl} / \mathrm{DIBAL}-\mathrm{H}, \mathrm{TMEDA}, \mathrm{FeCl}_{3} / \mathrm{THF},-10^{\circ} \mathrm{C}$ to $0^{\circ} \mathrm{C}, 1$ day; $c f$. Ref. ${ }^{[15]}$

[c] Isolated yield after redistillation of several combined forerunnings.

[d] $\mathrm{Mg}$ turnings $/ \mathrm{Me}_{3} \mathrm{SiCl} / \mathrm{HMPA}, 100^{\circ} \mathrm{C}, 2$ days; $c f$. Ref. ${ }^{[9]}$

[e] $\mathrm{Mg}$ powder/ $/ \mathrm{Me}_{3} \mathrm{SiCl} / \mathrm{HMPA}-\mathrm{THF}, 100^{\circ} \mathrm{C}, 2$ days; $c f$. Ref. ${ }^{[26]}$

[f] $\mathrm{X}=\mathrm{I}$.

[g] Yields were estimated from the ${ }^{1} \mathrm{H}$ NMR spectra of the crude product mixtures.

[h] Yields suffer from poor reproducibility.

[i] $\mathrm{Mg} / \mathrm{Me}_{3} \mathrm{SiCl} / \mathrm{HMPA}-\mathrm{THF} ; c f$. Ref. ${ }^{[24]}$

acid catalyst ( $c f . \mathbf{C}$ for the activation of 1,2-diazines; Scheme 1). ${ }^{[8]}$

The currently best-established synthesis protocol for compound $\mathbf{1}$, which starts from 1,2-dichlorobenzene, $\mathrm{Mg}$ turnings, and $\mathrm{Me}_{3} \mathrm{SiCl}$, suffers from two major disadvantages: (i) the use of the toxic and cancerogenic solvent hexamethylphosphoramide (HMPA) is necessary, and (ii) the transformation requires high temperature $\left(100^{\circ} \mathrm{C}\right)$ and a long reaction time (2 days). ${ }^{[9]}$ To avoid the use of HMPA, 1 can alternatively be prepared from 1,2-dibromobenzene, tert-butyllithium (4 equiv.), and an excess of $\mathrm{Me}_{3} \mathrm{SiOTf} \quad\left(\mathrm{OTf}=\right.$ triflate; $\left.\mathrm{Et}_{2} \mathrm{O}-\mathrm{THF},-120^{\circ} \mathrm{C}\right) .{ }^{[10]}$ Here, the use of $\mathrm{Me}_{3} \mathrm{SiCl}$ does not give 1 in appreciable amounts, which, together with the fact that tertbutyllithium is employed instead of $\mathrm{Mg}$, renders this methodology rather expensive. Given this background, [2-(hydroxydimethylsilyl)phenyl](phenyl)iodonium triflate has been suggested as a substitute for $\mathbf{A}{ }^{[11]}$ because the synthesis of this new benzyne precursor proceeds via 1,2-bis(dimethylsilyl)benzene, which is sterically less encumbered than $\mathbf{1}$ and accessible from 1,2-dibromobenzene/Mg/ $\mathrm{Me}_{2}(\mathrm{H}) \mathrm{SiCl}$ in THF. ${ }^{[12]}$ For the synthesis of $\mathbf{B}$, the silyl derivative 1 could, in principle, be replaced by 1,2bis(trimethylstannyl)benzene. ${ }^{[13]}$ However, in this case 4 equivalents of $\mathrm{Me}_{3} \mathrm{SnCl}$ are generated as a side product of the assembly of the 9,10-dihydro-9,10-diboraanthracene scaffold with $\mathrm{BCl}_{3}$. $\mathrm{Me}_{3} \mathrm{SnCl}$ is not only toxic but also difficult to remove quantitatively from the resulting 9,10-dichloro-9,10-dihydro-9,10-diboraanthracene intermediate.
The synthesis protocols for $\mathbf{1}$ reviewed thus far demonstrate that substantial efforts have already been spent on optimizing the reagents and the reaction conditions. However, in the case of the Grignard approaches, only one study is known which focuses on the arguably most influential parameter, i.e., the activity of the magnesium employed: Wegner et al. applied the diisobutylaluminium hydride (DIBAL-H) activation procedure ${ }^{[14]}$ to magnesium powder and showed that a subsequent Grignard reaction with $\mathrm{Me}_{3} \mathrm{SiCl}$ in $\mathrm{THF}$ provided $\mathbf{1}$ in $37 \%$ yield (reflux, $45 \mathrm{~min}) .^{[15]}$ They have also shown that a catalytic amount of anhydrous $\mathrm{FeCl}_{3}(3 \mathrm{~mol} \%)^{[16]}$ allows one to conduct the silylation at $-10^{\circ} \mathrm{C}(1$ day; yield of $\mathbf{1}$ : $41 \%$ ) and thereby to prepare a number of alkyl-, alkoxy- or fluorine-substituted 1,2-bis(trimethylsilyl)benzenes.

Herein, we will show that the reaction time of the iron-catalyzed approach and the associated yield of $\mathbf{1}$ can be improved further by using (i) Rieke-Mg $\left(\mathrm{Mg}^{\mathrm{R}}\right)^{[17]}$ or (ii) $\mathrm{Mg}$ turnings in the presence of 1,2-dibromoethane as an entrainer for continuous activation $\left(\mathrm{Mg}^{\mathrm{e}} ;{ }^{[18]}\right.$ Table 1$)$. Both protocols also provide convenient high-yield routes to 1,2,4,5-tetrakis(trimethylsilyl)benzene and first time access to 4-fluoro-1,2bis(trimethylsilyl)benzene, 4-chloro-1,2-bis(trimethylsilyl)benzene as well as 4,5-dichloro-1,2-bis(trimethylsilyl)benzene. Especially the latter two compounds are relevant, because they offer the possibility of extensive functionalization via transition metal-mediated $\mathrm{C}-\mathrm{C}$ coupling reactions. ${ }^{[19]}$ In those cases where the substitution pattern on the phenylene ring is not 
an issue (e.g., numerous applications of $\mathbf{B}$; Scheme 1 ), the readily available 1,2-dibromo-4,5-dimethylbenzene $^{[20]}$ could be an economically attractive alternative to the parent 1,2-dibromobenzene as a starting material. Thus, we also investigated the reaction between $\mathrm{Mg}^{\mathrm{R}} / \mathrm{Mg}^{\mathrm{e}}, \mathrm{Me}_{3} \mathrm{SiCl}$, and 1,2-dibromo-4,5-dimethylbenzene.

\section{Results and Discussion}

The slurry of $\mathrm{Mg}^{\mathrm{R}}$ in THF used in our investigations was prepared from $\mathrm{MgCl}_{2}$ and 1.5 equivalents of $\mathrm{K}$; excess $\mathrm{MgCl}_{2}$ as well as the generated $\mathrm{KCl}$ were not removed ( $c f$. the Experimental Section). In a previous report, the presence of $\mathrm{KI}$ in the $\mathrm{Mg}^{\mathrm{R}}$-forming step has been described to produce a particularly reactive metal powder. ${ }^{[21]}$ For the synthesis of the compounds discussed here, such a beneficial effect could not be confirmed.

In the entrainment approach, continuous activation at room temperature was achieved by dropwise addition of 1,2-dibromoethane to a mixture of $\mathrm{Mg}$ turnings, the respective 1,2-dibromobenzene derivative, and excess $\mathrm{Me}_{3} \mathrm{SiCl}$ in THF. An amount of $0.2-$ 0.8 equivalents of the entrainer was sufficient for quantitative conversion. In contrast to the Rieke-Mg protocol, which requires carefully dried solvent and the strict maintenance of inert conditions, the THF (p.a. grade) employed in the entrainment method was used as received from the commercial supplier and the glassware was just briefly flushed with $\mathrm{N}_{2}$.

The reaction of $\mathrm{Mg}^{\mathrm{R}} / \mathrm{Mg}^{\mathrm{e}}$ with 1,2-dibromobenzene and excess $\mathrm{Me}_{3} \mathrm{SiCl}$ in $\mathrm{THF}$ at $0{ }^{\circ} \mathrm{C} / 20^{\circ} \mathrm{C}$ gave 1,2 -bis(trimethylsilyl)benzene (1) in $65 \% / 62 \%$ yield (Scheme 2; Table 1). ${ }^{[22]}$ In terms of solvent toxicity as well as the required reaction temperatures and times, both protocols offer major advantages over the established method ${ }^{[9]}$ while comparable product yields are achieved (Table 1).

When applied to 1,2,4,5-tetrabromobenzene, both procedures also work faithfully for the preparation of 1,2,4,5-tetrakis(trimethylsilyl)benzene (2; Scheme 2), a versatile building block for linear polycyclic aromatic compounds. ${ }^{[23,24]}$ The obtained yields of $2\left(\mathrm{Mg}^{\mathrm{R}}\right.$ : $80 \%, \mathrm{Mg}^{\mathrm{e}}: 54 \%$; Table 1) are substantially higher than the yields of alternative synthesis methods $(\mathrm{Mg} /$ 1,2,4,5- $-\mathrm{Br}_{4} \mathrm{C}_{6} \mathrm{H}_{2} / \mathrm{Me}_{3} \mathrm{SiCl} / \mathrm{THF}$, reflux, 2 days: $20 \%$; $^{[25]}$ $\mathrm{Mg} / 1,2,4,5-\mathrm{Cl}_{4} \mathrm{C}_{6} \mathrm{H}_{2} / \mathrm{Me}_{3} \mathrm{SiCl} / \mathrm{HMPA}-\mathrm{THF}, \quad 100^{\circ} \mathrm{C}$, 2 days: $\quad 49 \%$; $; 3,24,26] \quad \mathrm{Mg} / 1,2,4,5-\mathrm{Br}_{4} \mathrm{C}_{6} \mathrm{H}_{2} / \mathrm{Me} 3 \mathrm{SiCl} /$ DIBAL-H, TMEDA, $\mathrm{FeCl}_{3} / \mathrm{THF},-10^{\circ} \mathrm{C}$ to $0^{\circ} \mathrm{C}$, 1 day: $38 \%{ }^{[15]}$ ).

Encouraged by these positive results, we next tested whether the use of $\mathrm{Mg}^{\mathrm{R}}$ also provides a route for the six-fold silylation of hexabromobenzene with $\mathrm{Me}_{3} \mathrm{SiCl}^{[27]}$ The target compound, hexakis(trimethylsilyl)benzene, has already been described by Sakurai<smiles>Brc1ccccc1Br</smiles><smiles>Brc1cc(Br)c(Br)cc1Br</smiles><smiles>[C]1[CH]CC1</smiles><smiles>Brc1c(Br)c(Br)c(Br)c(Br)c1Br</smiles>

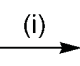

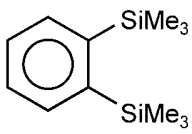

1<smiles>C[SiH2]c1cc([SiH3])c([SiH3]C)cc1[SiH3]</smiles>

2<smiles>C[SiH2]C(=C=C([SiH2]C)C(=C=C([SiH3])[SiH3])[SiH2]C)[SiH2]C</smiles>

3
Scheme 2. Synthesis of the 1,2-bis(trimethylsilyl)benzenes $\mathbf{1}$ and 2 in THF; reaction of hexabromobenzene with $\mathrm{Me}_{3} \mathrm{SiCl}$ and $\mathrm{Mg}^{\mathrm{R}}$ in THF. (i) $\mathrm{Mg}^{\mathrm{R}}:+5 \mathrm{Me}_{3} \mathrm{SiCl},+2.5 \mathrm{Mg}^{\mathrm{R}}, 0^{\circ} \mathrm{C}$, $1.5 \mathrm{~h}, 65 \% ; \mathrm{Mg}^{\mathrm{e}}:+8 \mathrm{Me}_{3} \mathrm{SiCl},+3 \mathrm{Mg},+0.21,2-\mathrm{C}_{2} \mathrm{H}_{4} \mathrm{Br}_{2}$, room temperature, $30 \mathrm{~min}, 62 \%$. (ii) $\mathrm{Mg}^{\mathrm{R}}:+11 \mathrm{Me}_{3} \mathrm{SiCl}$, $+9 \mathrm{Mg}^{\mathrm{R}}, \quad 0^{\circ} \mathrm{C} \rightarrow$ room temperature, $3.5 \mathrm{~h}, 80 \% ; \mathrm{Mg}^{\mathrm{e}}$ : $+12 \mathrm{Me}_{3} \mathrm{SiCl},+8 \mathrm{Mg},+1.51,2-\mathrm{C}_{2} \mathrm{H}_{4} \mathrm{Br}_{2}$, room temperature, $2 \mathrm{~h}, 54 \%$. (iii) $\mathrm{Mg}^{\mathrm{R}}:+30 \mathrm{Me}_{3} \mathrm{SiCl},+15 \mathrm{Mg}^{\mathrm{R}}, 0^{\circ} \mathrm{C} \rightarrow$ room temperature, $1.5 \mathrm{~h} ; 3$ could be detected as one of several components in the product mixture.

et al., who started from hexabromobenzene and developed a three-step synthesis sequence via hexakis(dimethylsilyl)benzene. ${ }^{[28]}$ Previous attempts of Gilman et al. at the direct trimethylsilylation of hexabromobenzene $\left(\mathrm{Mg} / \mathrm{Me}_{3} \mathrm{SiCl} / \mathrm{THF}\right.$, reflux, $\left.12 \mathrm{~h}\right)$ have failed. ${ }^{[29,30]}$ The only well-defined product that could be isolated in small amounts from the reaction mixtures, was 1,1,3,4,6,6-hexakis(trimethylsilyl)-1,2,4,5hexatetraene (3; Scheme 2). ${ }^{[29,30]}$ Since hexakis(trimethylsilyl)benzene is known to undergo a rearrangement reaction to afford $\mathbf{3}$ upon thermal treatment, ${ }^{[28]}$ we reckoned that the lower reaction temperature required for the Rieke-Mg protocols might offer an opportunity to prepare hexakis(trimethylsilyl)benzene in one step. However, the reaction with $\mathrm{Mg}^{\mathrm{R}}$ took a similar course as the Gilman experiments and $\mathbf{3}$ was obtained as one of several products (Scheme 2).

Apart from the parent 1,2-bis(trimethylsilyl)benzene (1), the halogenated derivatives 4,5 , and $\mathbf{8}$ were also readily prepared from the corresponding 1,2-dibromo- and 1,2-diiodobenzenes (Scheme 3; Table 1). The use of 1,2-dibromo-4-chlorobenzene in the synthesis of 8 with $\mathrm{Mg}^{\mathrm{R}}$ led to an undesired partial $\mathrm{Cl} /$ $\mathrm{SiMe}_{3}$ exchange even though the reaction temperature was lowered to $-40^{\circ} \mathrm{C}$. This problem was solved by using 4-chloro-1,2-diiodobenzene instead. With the $\mathrm{Mg}^{\mathrm{e}}$ method, we were surprised to find that 4-chloro1,2-diiodobenzene turned out to be far less reactive 
<smiles>Cc1cc(Cl)c(C(C)C)cc1Cl</smiles>

4<smiles>Cc1ccc(F)cc1C(C)C</smiles><smiles>CCCCCCCC</smiles>
product distribution [\%]: 55 $\left({ }^{1} \mathrm{H},{ }^{19} \mathrm{~F}\right.$ NMR $)$<smiles>Cc1cc(Cl)ccc1S(C)(C)C</smiles>

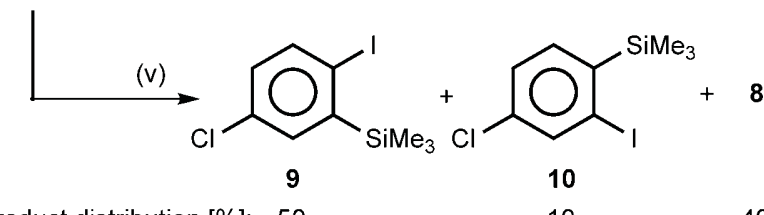
product distribution [\%]: 50 ( ${ }^{1} \mathrm{H}$ NMR)<smiles>Cc1cc(C)c(C)cc1C</smiles>

11

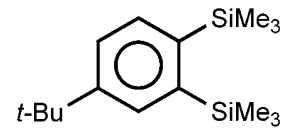

12
Scheme 3. Synthesis of the halogenated 1,2-bis(trimethylsilyl)benzenes $\mathbf{4}, \mathbf{5}$, and $\mathbf{8}$ in THF; product distribution of the corresponding reactions with 1.1 equivalents of $\mathrm{Mg}^{\mathrm{R}}$ in THF; drawings of $\mathbf{1 1}$ and 12. (i) $\mathrm{Mg}^{\mathrm{R}}:+10 \mathrm{Me}_{3} \mathrm{SiCl},+3 \mathrm{Mg}^{\mathrm{R}}$, $-40^{\circ} \mathrm{C} \rightarrow$ room temperature, $2 \mathrm{~h}, 70 \% ; \mathrm{Mg}^{\mathrm{e}}:+8 \mathrm{Me}_{3} \mathrm{SiCl}$, $+4 \mathrm{Mg}$, $+0.41,2-\mathrm{C}_{2} \mathrm{H}_{4} \mathrm{Br}_{2}$, room temperature, $45 \mathrm{~min}, 67 \%$. (ii) $\mathrm{Mg}^{\mathrm{R}}:+7 \mathrm{Me}_{3} \mathrm{SiCl},+3 \mathrm{Mg}^{\mathrm{R}}$, room temperature $\rightarrow 40^{\circ} \mathrm{C}$, $1 \mathrm{~h}, 53 \% ; \mathrm{Mg}^{\mathrm{e}}:+8 \mathrm{Me}_{3} \mathrm{SiCl},+4 \mathrm{Mg},+0.41,2-\mathrm{C}_{2} \mathrm{H}_{4} \mathrm{Br}_{2}$, room temperature, $45 \mathrm{~min}, 56 \%$. (iii) $\mathrm{Mg}^{\mathrm{R}}:+5 \mathrm{Me}_{3} \mathrm{SiCl},+1.1 \mathrm{Mg}^{\mathrm{R}}$, room temperature $\rightarrow 40^{\circ} \mathrm{C}, 1 \mathrm{~h}$. (iv) $\mathrm{Mg}^{\mathrm{R}}$ : $+9 \mathrm{Me}_{3} \mathrm{SiCl}$, $+2.5 \mathrm{Mg}^{\mathrm{R}}, \quad-40^{\circ} \mathrm{C} \rightarrow$ room temperature, $2 \mathrm{~h}, 60 \%$; $\mathrm{Mg}^{\mathrm{e}}$ : $+10 \mathrm{Me}_{3} \mathrm{SiCl},+15 \mathrm{Mg},+101,2-\mathrm{C}_{2} \mathrm{H}_{4} \mathrm{Br}_{2}$, room temperature, $4 \mathrm{~h}, 70 \%$. (v) $\mathrm{Mg}^{\mathrm{R}}:+5 \mathrm{Me}_{3} \mathrm{SiCl},+1.1 \mathrm{Mg}^{\mathrm{R}},-40^{\circ} \mathrm{C} \rightarrow$ room temperature, $2.5 \mathrm{~h}$.

than 1,2-dibromo-4-chlorobenzene, requiring 15 equivalents of $\mathrm{Mg}$ and 10 equivalents of entrainer for full conversion. At the same time, the chemoselectivity of the halogen/SiMe 3 exchange was comparable to that of 1,2-dibromo-4-chlorobenzene. Attempts at the synthesis of 4-bromo-1,2-bis(trimethylsilyl)ben- zene starting from 4-bromo-1,2-diiodobenzene and $\mathrm{Mg}^{\mathrm{R}}$ failed due to pronounced $\mathrm{Br} / \mathrm{SiMe}_{3}$ exchange.

In summary, selectivity was not an issue in the case of the transformations 1,2-dibromo-4,5-dichlorobenzene $\rightarrow \mathbf{4}\left(\mathrm{Mg}^{\mathrm{R}}, \mathrm{Mg}^{\mathrm{e}}\right)$, 1,2-dibromo-4-fluorobenzene $\rightarrow \mathbf{5}$ $\left(\mathrm{Mg}^{\mathrm{R}}, \quad \mathrm{Mg}^{\mathrm{e}}\right), \quad$ and 4-chloro-1,2-diiodobenzene $\rightarrow \mathbf{8}$ $\left(\mathrm{Mg}^{\mathrm{R}}\right)$.

Compounds $\mathbf{4}, \mathbf{5}$, and $\mathbf{8}$ have been characterized by (heteronuclear) NMR spectroscopy and combustion analysis ( $c f$. the Supporting Information). Moreover, in the case of $\mathbf{4}$ an X-ray crystal structure analysis was performed (Figure 1). Considerable steric strain within this molecule can be inferred from the elongated $\mathrm{Si}-\mathrm{C}_{i p s o}$ distances, which possess an even larger value $[1.907(5) \AA]$ than the average $\mathrm{Si}-\mathrm{CH}_{3}$ bond length $[1.872(6) \AA]$. Moreover, the $\mathrm{Si}(1)-\mathrm{C}(1)-\mathrm{C}(2)$ and $\mathrm{Si}(2)-\mathrm{C}(2)-\mathrm{C}(1)$ bond angles are expanded to $126.7(4)^{\circ}$ and $129.2(4)^{\circ}$, respectively, and the torsion angle $\mathrm{Si}(1)-\mathrm{C}(1)-\mathrm{C}(2)-\mathrm{Si}(2)$ of $-10.4(8)^{\circ}$ deviates from the ideal value of $0^{\circ}$.

In order to find out whether the behavior of the bromo (iodo) substituent in the para position to the fluorine (chlorine) atom is different from the one in the meta position, we repeated the reaction of 1,2-dibromo-4-fluorobenzene (4-chloro-1,2-diiodobenzene) with only 1.1 equivalents of $\mathrm{Mg}$. In this case, only the Rieke-Mg approach was applied, because it allows easy control of the actual amount of active metal even on a very small scale (Scheme 3). About onequarter (one-half) of the organic starting material remained unreacted. Consequently, significant amounts of the halogenated 1,2-bis(trimethylsilyl)benzene $\mathbf{5}$

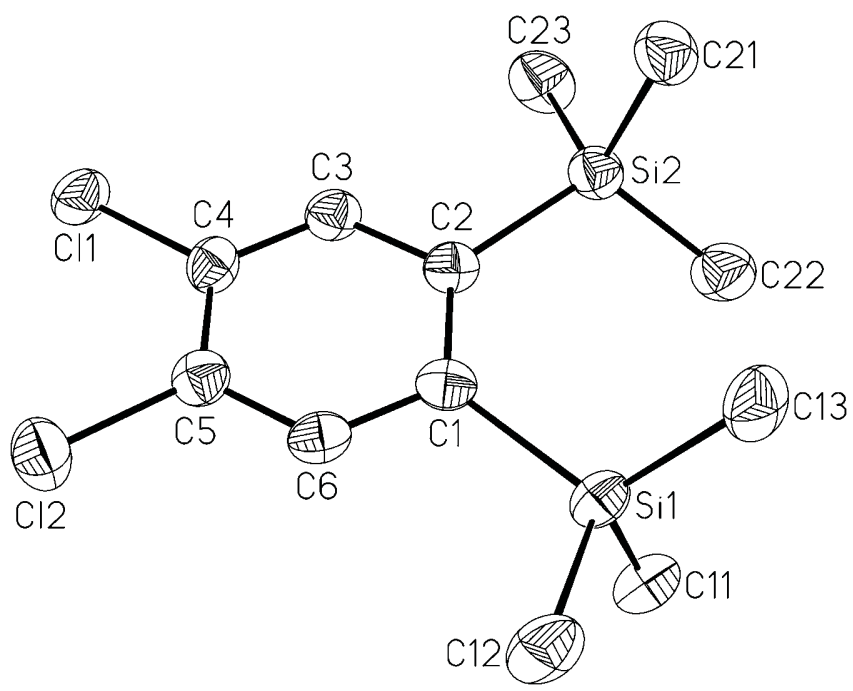

Figure 1. Molecular structure and numbering scheme of compound 4. Displacement ellipsoids are drawn at the $50 \%$ probability level. H-atoms have been omitted for clarity. Selected bond lengths $(\AA)$, bond angles (deg), and torsion angle (deg): $\mathrm{Si}(1)-\mathrm{C}(1)=1.908(5), \quad \mathrm{Si}(2)-\mathrm{C}(2)=1.905(5)$; $\mathrm{Si}(1)-\mathrm{C}(1)-\mathrm{C}(2)=126.7(4), \quad \mathrm{Si}(2)-\mathrm{C}(2)-\mathrm{C}(1)=129.2(4)$; $\mathrm{Si}(1)-\mathrm{C}(1)-\mathrm{C}(2)-\mathrm{Si}(2)=-10.4(8)$. 
(8) were formed in both cases; the product distribution of both reactions was determined by NMR spectroscopy and is shown in Scheme 3. Compared to 4chloro-1,2-diiodobenzene, 1,2-dibromo-4-fluorobenzene thus shows (i) a higher degree of overall conversion, (ii) a lower degree of 1,2-disilylation, and (iii) a considerably lower selectivity between the two monosilylated isomers.

The assignment of the structures $\mathbf{6}$ and 9 to the major monosilylated isomers is based on ${ }^{1} \mathrm{H}-{ }^{1} \mathrm{H}-$ COSY, ${ }^{1} \mathrm{H}-{ }^{1} \mathrm{H}$-ROESY, and ${ }^{1} \mathrm{H}-{ }^{29} \mathrm{Si}-\mathrm{HETCOR}$ NMR experiments and will be explained for 1-bromo-4fluoro-2-trimethylsilylbenzene/2-bromo-4-fluoro-1-trimethylsilylbenzene (6/7), but similar arguments apply to 9/10 (for plots of the spectra see the Supporting Information). Both isomers $\mathbf{6 / 7}$ give rise to three signals in the aromatic region of the ${ }^{1} \mathrm{H}$ NMR spectrum. The major isomer shows: (i) one multiplet at $6.90 \mathrm{ppm}$, (ii) one doublet of doublets at $7.13 \mathrm{ppm}$, and (iii) one doublet of doublets at $7.47 \mathrm{ppm}$. Values of ${ }^{3} J_{\mathrm{F}, \mathrm{H}}=$ $8.6 \mathrm{~Hz}$ and ${ }^{4} J_{\mathrm{FH}}=4.8 \mathrm{~Hz}$ are evident from the major ${ }^{19} \mathrm{~F}$ NMR signal. Since a ${ }^{4} J_{\mathrm{H}, \mathrm{F}}=4.8 \mathrm{~Hz}$ coupling only appears in the $7.47 \mathrm{ppm}{ }^{1} \mathrm{H}$ NMR resonance, we assign this signal to the $\mathrm{H}-6$ proton. The ${ }^{1} \mathrm{H}-{ }^{1} \mathrm{H}-\mathrm{COSY}$ spectrum, in turn, allows us to assign the $6.90 \mathrm{ppm}$ and the $7.13 \mathrm{ppm}$ resonances to $\mathrm{H}-5$ and $\mathrm{H}-3$, respectively. The H-3 signal shows a cross peak to the major $\mathrm{SiMe}_{3}$ resonance in the ${ }^{1} \mathrm{H}-{ }^{1} \mathrm{H}-\mathrm{ROESY}$ and in the ${ }^{1} \mathrm{H}_{-}{ }^{29} \mathrm{Si}-\mathrm{HETCOR}$ NMR spectrum. We therefore conclude that the $\mathrm{SiMe}_{3}$ group of the major isomer occupies the 2-position of the benzene ring ( $c f .6$ ). Consistent with that, the $\mathrm{SiMe}_{3}$ resonance of the minor isomer 7 shows cross-peaks exclusively to the signal of the H-6 proton.

1,2-Dibromo-4,5-dimethylbenzene reacts with $\mathrm{Me}_{3} \mathrm{SiCl}$ and $\mathrm{Mg}^{\mathrm{R}}$ at room temperature in THF to give 1,2-bis(trimethylsilyl)-4,5-dimethylbenzene (11; Scheme 3) in amounts of $10 \%-40 \%$. The following features of this transformation are remarkable: (i) The yields of $\mathbf{1 1}$ are low, even though the related compound 1,2,4,5-tetrakis(trimethylsilyl)benzene is formed in $80 \%$ yield under similar reaction conditions. (ii) The yields of $\mathbf{1 1}$ suffer from poor reproducibility, which is most likely due to different and hardto-control surface structures of the $\mathrm{Mg}^{\mathrm{R}}$ employed (this is not an issue in the cases discussed before). (iii) We do not observe major by-products, but after a period of clean formation of $\mathbf{1 1}$, the reaction comes to a halt. Application of the Rieke-Mg protocol to 1,2dibromo-4-tert-butylbenzene did not lead to the target compound 11, even at elevated temperatures.

The entrainment method, in contrast, results in a quantitative consumption of 1,2-dibromo-4,5-dimethylbenzene as well as 1,2-dibromo-4-tert-butylbenzene already at room temperature. In both cases, complex product mixtures are formed, the major constituents being $\mathbf{1 1}(<10 \%) / 2,3,6,7$-tetramethylbiphe- nylene (5\%) and 4-tert-butyl-1,2-bis(trimethylsilyl)benzene $(\mathbf{1 2} ;<10 \%)$ /di-tert-butylbiphenylenes $(5 \%)$, respectively (Scheme 3; Table 1).

\section{Conclusions}

1,2-Bis(trimethylsilyl)benzene and 1,2,4,5-tetrakis(trimethylsilyl)benzene have been conveniently prepared from the corresponding bromobenzenes and $\mathrm{Me}_{3} \mathrm{SiCl}$ in Grignard-type reactions, i.e., via the Rieke- $\mathrm{Mg}$ method $\left(\mathrm{Mg}^{\mathrm{R}}\right)$ and the entrainment method $\left(\mathrm{Mg}^{\mathrm{e}}\right.$; entrainer: 1,2-dibromoethane). One important improvement with respect to the currently best-established synthesis protocol for 1,2-bis(trimethylsilyl)benzene lies in the fact that the syntheses can be carried out in THF rather than in the cancerogenic solvent HMPA. Moreover, the reactions readily proceed at room temperature or below, as opposed to $100^{\circ} \mathrm{C}$ in the HMPA method, and the reaction times are reduced from 2 days to 1.5 hours $\left(\mathrm{Mg}^{\mathrm{R}}\right)$ to 30 minutes $\left(\mathrm{Mg}^{\mathrm{e}}\right)$. The yields obtained are comparable for all three protocols. We are aware that bromobenzenes are more costly than the chlorobenzenes employed in the HMPA route, however, this argument is more than outweighed by the gain in safety and time efficiency.

As a result of the milder reaction conditions, functionalized 1,2-bis(trimethylsilyl)benzenes bearing fluoro or chloro substituents at their aromatic rings are also accessible with high selectivity and yields. Thus, a broad application of these 1,2-bis(trimethylsilyl)benzene derivatives in the field of benzyne chemistry, organic optoelectronic materials and catalysis can be envisaged.

\section{Experimental Section}

\section{General Remarks}

All reactions using $\mathrm{Mg}^{\mathrm{R}}$ were carried out under a nitrogen atmosphere using Schlenk techniques and carefully dried solvents. $\mathrm{Me}_{3} \mathrm{SiCl}$ was stored over $\mathrm{CaH}_{2}$ and transferred by pipette into the reaction flask or dropping funnel. All reactions using $\mathrm{Mg}^{\mathrm{e}}$ were carried out in glassware that had been briefly flushed with $\mathrm{N}_{2}$. THF (p.a. grade, stabilized with $0.025 \%$ BHT) was purchased from Acros Organics (Geel, Belgium) and stored over $\mathrm{KOH} . \mathrm{Me}_{3} \mathrm{SiCl}$ was obtained from Apollo Scientific Ltd. (Stockport, UK) and used as received. 1,2-Dibromo-4,5-dichlorobenzene, ${ }^{[31]}$ 4-chloro-1,2-diiodobenzene, ${ }^{[32]}$ and 4-bromo-1,2-diiodobenzene ${ }^{[32]}$ were synthesized according to literature procedures.

\section{Preparation of Rieke-Magnesium $\left(\mathbf{M g}^{\mathrm{R}}\right)$}

In a representative procedure, a stirred mixture of THF $(800 \mathrm{~mL})$, potassium $(36.5 \mathrm{~g}, 934 \mathrm{mmol})$, and anhydrous $\mathrm{MgCl}_{2}(61.0 \mathrm{~g}, 641 \mathrm{mmol})$ was carefully heated to reflux for 
$3 \mathrm{~h}$. The resulting dark salt-containing $\mathrm{Mg}^{\mathrm{R}}$ slurry was directly used for further transformations.

\section{Synthesis of 1,2-Bis(trimethylsilyl)benzene (1) via $\mathbf{M g}^{\mathrm{R}}$}

A mixture of 1,2-dibromobenzene $(24.5 \mathrm{~mL}, \quad 48.0 \mathrm{~g}$, $203 \mathrm{mmol}), \mathrm{Me}_{3} \mathrm{SiCl}(135.0 \mathrm{~mL}, 115.6 \mathrm{~g}, 1064 \mathrm{mmol})$, and THF $(150 \mathrm{~mL})$ was added dropwise at $0{ }^{\circ} \mathrm{C}$ over $1 \mathrm{~h}$ to a freshly prepared stirred suspension of $\mathrm{Mg}^{\mathrm{R}}$ in THF $(800 \mathrm{~mL}$, $0.584 \mathrm{M}, 467 \mathrm{mmol})$. The slurry was stirred for further $30 \mathrm{~min}$ at $0{ }^{\circ} \mathrm{C}$ and then carefully quenched under nitrogen with a saturated aqueous solution of $\mathrm{NaHCO}_{3}(300 \mathrm{~mL})$. The formation of two phases was observed, which were separated with a separation funnel. The aqueous phase was extracted with hexane $(5 \times 40 \mathrm{~mL})$, the THF phase and the extracts were combined, washed with water $(5 \times 40 \mathrm{~mL})$, dried over anhydrous $\mathrm{MgSO}_{4}$, and filtered. All volatiles were removed from the filtrate under vacuum to obtain a mixture of 1 (70\%; NMR spectroscopic control) and $\mathrm{PhSiMe}_{3}(30 \%)$ as a pale orange oil. Product $\mathbf{1}$ was isolated as a colorless liquid by fractional distillation under reduced pressure (60$65^{\circ} \mathrm{C}, 10^{-2}$ Torr); yield: $23.53 \mathrm{~g}(52 \%)$. Note: The overall yield can be increased to approx. $65 \%$ when the combined forerunnings of several distillations are redistilled.

\section{Synthesis of 1,2-Bis(trimethylsilyl)benzene (1) via $\mathbf{M g}^{\mathrm{e}}$}

Mg turnings $(3.03 \mathrm{~g}, 125 \mathrm{mmol})$ were covered with $\mathrm{THF}$ $(100 \mathrm{~mL})$ and treated with neat $\mathrm{Me}_{3} \mathrm{SiCl}(42.2 \mathrm{~mL}, 36.1 \mathrm{~g}$, $332 \mathrm{mmol})$ and 1,2-dibromobenzene $(5.00 \mathrm{~mL}, \quad 9.78 \mathrm{~g}$, $41.5 \mathrm{mmol}$ ). A temperature of approximately $20^{\circ} \mathrm{C}$ was maintained by means of a water bath throughout the reaction time, because otherwise the mixture warms perceptibly after an induction period of about $5 \mathrm{~min}$. A solution of 1,2dibromoethane $(0.716 \mathrm{~mL}, 1.56 \mathrm{~g}, 8.30 \mathrm{mmol})$ in THF $(10 \mathrm{~mL})$ was added dropwise to the vigorously stirred slurry over $30 \mathrm{~min}$. All volatiles were removed under vacuum and the remaining solid residue was treated at $0{ }^{\circ} \mathrm{C}$ with hexane $(60 \mathrm{~mL})$ and water $(60 \mathrm{~mL})$. The two phases were separated and the aqueous phase was extracted with hexane $(2 \times$ $20 \mathrm{~mL}$ ). The combined organic layers were washed with water $(4 \times 20 \mathrm{~mL})$, dried over anhydrous $\mathrm{MgSO}_{4}$, filtered, and all volatiles were removed from the filtrate under vacuum. The remaining orange oil was fractionally distilled under reduced pressure $\left(60-65^{\circ} \mathrm{C}, 10^{-2}\right.$ Torr $)$ to afford $\mathbf{1}$ as a colorless oil; yield: $5.69 \mathrm{~g}(62 \%)$.

${ }^{1} \mathrm{H}$ and ${ }^{13} \mathrm{C}\left\{{ }^{1} \mathrm{H}\right\}$ NMR data were in accord with published values. $^{[10]}$

\section{Acknowledgements}

M.W. gratefully acknowledges financial support by the Beilstein-Institut, Frankfurt/Main, Germany, within the research collaboration NanoBiC. A.L. wishes to thank the Fonds der Chemischen Industrie for a Ph.D. grant. C.R. has been supported by the Studienstiftung des deutschen Volkes.

\section{References}

[1] a) D. Kaufmann, Chem. Ber. 1987, 120, 853-854; b) D. Kaufmann, Chem. Ber. 1987, 120, 901-905; c) U. Gross, D. Kaufmann, Chem. Ber. 1987, 120, 991-994; d) Y. Qin, G. Cheng, A. Sundararaman, F. Jäkle, J. Am. Chem. Soc. 2002, 124, 12672-12673; e) M. C. Haberecht, J. B. Heilmann, A. Haghiri, M. Bolte, J. W. Bats, H.-W. Lerner, M. C. Holthausen, M. Wagner, Z. Anorg. Allg. Chem. 2004, 630, 904-913.

[2] For selected reviews, see: a) Y. Hatanaka, T. Hiyama, Synlett 1991, 845-853; b) T. Hiyama, E. Shirakawa, Top. Curr. Chem. 2002, 219, 61-85.

[3] a) D. Häbich, F. Effenberger, Synthesis 1979, 841-876; b) M. Murata, K. Ota, H. Yamasaki, S. Watanabe, Y. Masuda, Synlett 2007, 1387-1390 and references cited therein.

[4] T. Kitamura, M. Yamane, J. Chem. Soc., Chem. Commun. 1995, 983-984.

[5] T. Kitamura, M. Yamane, K. Inoue, M. Todaka, N. Fukatsu, Z. Meng, Y. Fujiwara, J. Am. Chem. Soc. 1999, 121, 11674-11679.

[6] A. Lorbach, M. Bolte, H. Li, H.-W. Lerner, M. C. Holthausen, F. Jäkle, M. Wagner, Angew. Chem. 2009, 121, 4654-4658; Angew. Chem. Int. Ed. 2009, 48, 45844588.

[7] A. Lorbach, M. Bolte, H.-W. Lerner, M. Wagner, Organometallics 2010, 29, 5762-5765.

[8] a) S. N. Kessler, H. A. Wegner, Org. Lett. 2010, 12, 4062-4065; b) A. Lorbach, M. Bolte, H.-W. Lerner, M. Wagner, Chem. Commun. 2010, 46, 3592-3594.

[9] T. Kitamura, M. Todaka, Y. Fujiwara, Org. Synth. 2002, 78, 104-108.

[10] H. F. Bettinger, M. Filthaus, J. Org. Chem. 2007, 72, 9750-9752.

[11] T. Kitamura, Z. Meng, Y. Fujiwara, Tetrahedron Lett. 2000, 41, 6611-6614.

[12] W. Fink, Helv. Chim. Acta 1974, 57, 1010-1015.

[13] J. J. Eisch, B. W. Kotowicz, Eur. J. Inorg. Chem. 1998, $761-769$.

[14] U. Tilstam, H. Weinmann, Org. Process Res. Dev. 2002, 6, 906-910.

[15] S. L. Bader, S. N. Kessler, H. A. Wegner, Synthesis 2010, 2759-2762.

[16] a) B. Bogdanović, M. Schwickardi, Angew. Chem. 2000, 112, 4788-4790; Angew. Chem. Int. Ed. 2000, 39, 46104612; b) W. M. Czaplik, M. Mayer, A. Jacobi von Wangelin, Angew. Chem. 2009, 121, 616-620; Angew. Chem. Int. Ed. 2009, 48, 607-610.

[17] a) R. D. Rieke, P. M. Hudnall, J. Am. Chem. Soc. 1972, 94, 7178-7179; b) R. D. Rieke, Acc. Chem. Res. 1977, 10, 301-306; c) R. D. Rieke, S. E. Bales, P. M. Hudnall, 
T. P. Burns, G. S. Poindexter, Org. Synth. 1979, 59, $85-$ 92; d) R. D. Rieke, Science 1989, 246, 1260-1264.

[18] D. E. Pearson, D. Cowan, J. D. Beckler, J. Org. Chem. 1959, 24, 504-509.

[19] a) A. F. Littke, G. C. Fu, Angew. Chem. 2002, 114, 4350-4386; Angew. Chem. Int. Ed. 2002, 41, 41764211; b) R. B. Bedford, C. S. J. Cazin, D. Holder, Coord. Chem. Rev. 2004, 248, 2283-2321.

[20] P. R. Ashton, U. Girreser, D. Giuffrida, F. H. Kohnke, J. P. Mathias, F. M. Raymo, A. M. Z. Slawin, J. F. Stoddart, D. J. Williams, J. Am. Chem. Soc. 1993, 115, 54225429.

[21] R. D. Rieke, S. E. Bales, J. Chem. Soc., Chem. Commun. 1973, 879-880.

[22] Attempts to conduct these silylation protocols with the low-priced starting material 1,2-dichlorobenzene failed, even when higher reaction temperatures and/or longer reaction times were applied.

[23] C.-Y. Yick, S.-H. Chan, H. N. C. Wong, Tetrahedron Lett. 2000, 41, 5957-5961.

[24] S.-H. Chan, C.-Y. Yick, H. N. C. Wong, Tetrahedron 2002, 58, 9413-9422.
[25] H. Bock, W. Kaim, Z. Anorg. Allg. Chem. 1979, 459, 103-110.

[26] H. Bock, M. Ansari, N. Nagel, Z. Havlas, J. Organomet. Chem. 1995, 499, 63-71.

[27] Since the amount of entrainer required for the synthesis of 1,2,4,5-tetrakis(trimethylsilyl)benzene (2) is already one order of magnitude higher than the amount required for the preparation of 1,2-bis(trimethylsilyl)benzene (1), this experiment was not conducted with $\mathrm{Mg}^{\mathrm{e}}$.

[28] H. Sakurai, K. Ebata, C. Kabuto, A. Sekiguchi, J. Am. Chem. Soc. 1990, 112, 1799-1803.

[29] T. Brennan, H. Gilman, J. Organomet. Chem. 1968, 11, $625-626$.

[30] D. Ballard, T. Brennan, F. W. G. Fearon, K. Shiina, I. Haiduc, H. Gilman, Pure Appl. Chem. 1969, 19, 449472.

[31] F. Raymo, F. H. Kohnke, F. Cardullo, Tetrahedron 1992 , $48,6827-6838$.

[32] R. J. Perry, S. R. Turner, J. Org. Chem. 1991, 56, 65736579. 